\title{
Management and Outcome of Severe Sepsis and Septic Shock Patients
}

\author{
Sabitri Lamichhane, ${ }^{1}$ Nayan Manandhar, ${ }^{1}$ Shailendra Dhakal, ${ }^{2}$ Yagya Laxmi Shakya ${ }^{3}$ \\ ${ }^{1}$ Department of Pharmacy, Maharajgunj Medical Campus, Tribhuvan University, Kathmandu, ${ }^{2}$ Department \\ of Pharmacy, Universal College of Medical Sciences, Tribhuvan University, Bhairahawa, ${ }^{3}$ Department of \\ General Practice and Emergency Medicine, Tribhuvan University Teaching Hospital, Kathmandu, Nepal.
}

\begin{abstract}
Background: Severe sepsis and septic shock are major causes of morbidity and mortality worldwide and need immediate medical attention. Early recognition, fluid resuscitation and early antimicrobials are the mainstays of sepsis therapy. This study analyzed the management strategies of severe sepsis and septic shock and evaluated its impact.

Methods: A prospective study was conducted on patients admitted through emergency department of Tribhuvan University Teaching Hospital of Nepal, who were diagnosed with severe sepsis and septic shock.

Results: A total of 85 patients were diagnosed as severe sepsis and septic shock with 45 female patients and mean age 47.69 years ranging from 18 to 83 years. Pneumonia (45.9\%) was found to be the major source of infection. The most commonly prescribed antibiotics and vassopressor at emergency department were ceftriaxone (24.7\%) and norepinephrine (44.7\%) respectively. The mean length of stay in Emergency department was $13.01 \pm 7.03 \mathrm{~h}$, while it was $11.27 \pm 5.26$ days in hospital. A total of 31 (36.5\%) septic patients died. Deceased patients were found to have greater age, higher Acute Physiology and Chronic Health Evaluation II (APACHE II) score and presence of co-morbid conditions.

Conclusions: This study looked in-depth on management and outcome of patients with severe sepsis and septic shock. Mortality from severe sepsis and septic shock were high, but similar to other studies.

Keywords: Antimicrobial therapy; emergency department; mortality; septic shock; severe sepsis.
\end{abstract}

\section{INTRODUCTION}

Sepsis is defined as life-threatening organ dysfunction or tissue hypoperfusion caused by a deregulated host response to infection. ${ }^{1}$ It is estimated that more than 18 million individuals are affected annually. ${ }^{2}$ The associated mortality due to severe sepsis varies from $19 \%$ to $39 \% .^{3-5}$

The initial management is done in emergency department (ED) before referring to Intensive Care Unit (ICU). Studies have also reported increase in survival of patient with rapid initiation of appropriate antimicrobial therapy and supportive care. ${ }^{6,7}$ So far most of the studies from Nepal are observational studies in neonatal population. ${ }^{8-10}$ To the best of our knowledge, no studies have been conducted on overall management of sepsis and their associated mortality in adult population in Nepal.

This research was done to understand the management strategies and to evaluate the outcome of patients.

\section{METHODS}

This is a cross-sectional study conducted for the period of 5 months in Tribhuvan University Teaching Hospital (TUTH), Institute of Medicine, Kathmandu, Nepal. We studied the patients admitted to the emergency department. It was approved by Institutional Review Board of Institute of Medicine.

Severe sepsis is defined as sepsis associated with organ dysfunction or tissue hypoperfusion. Organ hypoperfusion for example 1) Increased blood lactate levels ( > $4 \mathrm{mg}$ / $\mathrm{dL}$ ) 2) Oliguria (urine output , $0.5 \mathrm{ml} / \mathrm{kg} / \mathrm{hr}$ for at least 2 hours) 3) Abnormal peripheral circulation, such as poor capillary refill, mottled skin 4) Acute alteration in mental status.

Organ dysfunction for example 1) The hematologic system; e.g., thrombocytopenia (platelet count $<100,000 \mathrm{ml} 21$ ), disseminated intravascular coagulation
DOI: http://dx.doi. org/10.3126/jnhrc.v16i2.20304
Correspondence: Ms Sabitri Lamichhane, Department of Pharmacy, Maharajgunj Medical Campus, Institute of Medicine, Tribhuvan University, Kathmandu, Nepal. Email:lamichhanesaabi99@gmail.com, Phone: +9779849516917. 
(International Normalized Ratio [INR] 1.5 or a partial thromboplastin time [PTT] .60 seconds) 2) The pulmonary system; e.g., acute respiratory distress syndrome dysfunction ( $\mathrm{PaO} 2 / \mathrm{FIO2}>300)$ 3) The renal system; e.g., acute renal failure (creatinine >.2.0 mg/dl) 4) The gastrointestinal system with hepatic dysfunction; e.g., hyperbilirubinemia (total plasma bilirubin $>2.0$ $\mathrm{mg} / \mathrm{dl}$ ) 5) The central nervous system; e.g. delirium 6) The cardiovascular system; hypotension (systolic blood pressure ,90 mm Hg, mean arterial pressure $40 \mathrm{~mm} \mathrm{Hg}$ from baseline measurements).

Septic shock is defined as refractory hypotension despite adequate volume resuscitation 1) A systolic blood pressure $<90 \mathrm{~mm} \mathrm{Hg} \mathrm{2)} \mathrm{A} \mathrm{mean} \mathrm{arterial} \mathrm{pressure}$ < $65 \mathrm{~mm} \mathrm{Hg}$, or a $40 \mathrm{~mm} \mathrm{Hg}$ drop in systolic blood pressure compared to baseline 3) Unresponsive to a fluid challenge of 20-40 ml, kg 4) Vasopressor dependency after adequate volume resuscitation. ${ }^{11}$

All adult patients above 18 years of age, presented to the emergency department with a diagnosis of severe sepsis and septic shock were included. Excluded cases were those: a) with age less than 18 years b) Patients transferred to another hospital within 24 hours of emergency department admission.

Information on demographics, patient history, vitals, provisional diagnosis, co-morbidities, source of infection, empirically administered antibiotics, time to antibiotics, fluids, vasopressors etc. were transcribed in proforma from ED records. Laboratory results were also documented in the proforma. Additional variables required to calculate Acute Physiology and Chronic Health Evaluation II (APACHE II) score ${ }^{12}$ were obtained from patient's clinical report during the first 24 hour of admission. Patients were followed until their discharge from the hospital. Results from blood cultures and microbiological analyses of urine, abscess, sputum, cerebrospinal fluid were collected. Disposition from the ED, length of stay in ED, length of stay in hospital was noted. The main outcome measure was in-hospital mortality.

Continuous variables are expressed as the mean \pm standard deviation (SD), whereas categorical variables are expressed as a proportion of the population. A twotailed sample t test compared age, length of stay in ED, overall length of stay in hospital, time to antibiotics, fluids and vasopressors, vital signs at presentation, laboratory values, APACHE II score, between survivors and non-survivors. A Pearson's chi-square test was used to compare differences in gender, severity of illness, source of infection, co-morbidities, previous antibiotic use, use of antibiotics, vasopressors, steroids, admission to various units between survivors and non-survivors. A 2- sided $P$ value of $<0.05$ was considered statistically significant. Collected data were entered and analyzed using computer based analysis software, SPSS version 20.

\section{RESULTS}

\section{Table 1. Demographic characteristics of patients.}

\begin{tabular}{lrrrr} 
Variables & $\begin{array}{r}\text { All } \\
\text { patients }\end{array}$ & Survivors & $\begin{array}{r}\text { Non- } \\
\text { survivors }\end{array}$ & $\begin{array}{r}P \\
\text { value }\end{array}$ \\
& $\mathrm{N}=85$ & $\mathrm{~N}=54$ & $\mathrm{~N}=31$ & \\
\hline Age (mean & $47.69 \pm$ & $41.54 \pm$ & $58.42 \pm$ & 0.001 \\
\pm SD) & 17.52 & 16.69 & 13.45 &
\end{tabular}

Sex (\%)

$\begin{array}{|lrlll|}\text { Male } & 40(47.0) & 25(46.2) & 12(38.7) & 0.184 \\ \text { Female } & 45 & 29(60.4) & 19(39.6) & \end{array}$

(52.9)

Provisional diagnosis at ED (\%)

\begin{tabular}{|lrrr|r} 
Severe & 35 & $25(71.4)$ & $10(28.6)$ & \\
sepsis & $(41.2)$ & & & 0.206 \\
\hline Septic shock & 50 & $29(58)$ & $21(42)$ & \\
& $(58.8)$ & & &
\end{tabular}

Co-morbidity, n (\%)

\begin{tabular}{|c|c|c|c|c|}
\hline $\begin{array}{l}\text { Hyperten- } \\
\text { sion }\end{array}$ & $\begin{array}{r}12 \\
(14.1)\end{array}$ & $8(66.6)$ & $4(33.4)$ & \\
\hline Diabetes & $\begin{array}{r}10 \\
(11.8)\end{array}$ & $5(50)$ & $5(50)$ & 0.004 \\
\hline COPD & $6(7.1)$ & $2(33.3)$ & $4(66.6)$ & \\
\hline $\begin{array}{l}\text { Renal dis- } \\
\text { ease }\end{array}$ & $6(7.1)$ & $4(66.6)$ & $2(33.3)$ & \\
\hline $\begin{array}{l}\text { Cardiovascu- } \\
\text { lar disease }\end{array}$ & $6(7.1)$ & 1 (16.7) & $5(83.3)$ & \\
\hline Tuberculosis & $4(4.7)$ & $4(100)$ & - & \\
\hline $\begin{array}{l}\text { Pulmonary } \\
\text { disease }\end{array}$ & $3(3.5)$ & $1(33.3)$ & $2(66.6)$ & \\
\hline Liver disease & $3(3.5)$ & $1(33.3)$ & $2(66.6)$ & \\
\hline Psychiatric & $2(2.4)$ & $2(100)$ & - & \\
\hline Others & $9(10.6)$ & $5(55.5)$ & $4(44.4)$ & \\
\hline None & $\begin{array}{r}24 \\
(28.2)\end{array}$ & $21(87.5)$ & $3(12.5)$ & \\
\hline $\begin{array}{l}\text { Previous use } \\
\text { of antibiot- } \\
\text { ics, n (\%) }\end{array}$ & $\begin{array}{r}22 \\
(25.9)\end{array}$ & $14(63.8)$ & $8(36.4)$ & 0.990 \\
\hline
\end{tabular}

Out of 140 septic patients presented to the ED, 35 patients were referred to another hospital due to unavailability of ICU beds and 20 patients died within six hours of arrival to the ED. So, a total of 85 patients identified with severe sepsis and septic shock were 
included for the study. The mean age of the patient was $47.69 \pm 17.52$, ranging from 18 to 83 years and there was a predominance of female patients $(52.9 \%)$. The most common underlying co-morbidity was hypertension (14.1\%) followed by diabetes $(11.8 \%)$. Severe sepsis was diagnosed in $41.2 \%$ whereas septic shock in $58.8 \%$ patients (Table 1 ).

The mean temperature was $99.19 \pm 2.82{ }^{\circ} \mathrm{C}$, MAP was $59.18 \pm 19.15 \mathrm{mmHg}$, lactate was $2.32 \pm 2.36 \mathrm{mmol} / \mathrm{L}$ and APACHE II score was $16.011 \pm 5.62$. There was a significant difference in the presence of co-morbid conditions between the survived and the deceased groups. Also, non- survivors had significantly higher APACHE II score, temperature, serum lactate and total bilirubin (Table 2 ).

Different microbiological samples were taken from the patients before or after antimicrobial therapy. Samples for blood cultures were taken before antimicrobial therapy in 48 patients. The most commonly performed investigations were blood cultures (59 patients), urine cultures (41 patients) and sputum cultures (44 patients). Pathogens were isolated in 21 patient's sample in total. Escherichia coli and Klebsiella pneumonia were the most commonly isolated organisms, each isolated in 5 patients (Figure 1).

Antimicrobial agents were initiated at ED after the initial diagnosis. For pneumonia, the most frequently used antibiotics was piperacillin/tazobactam (14 patients),

\begin{tabular}{|c|c|c|c|c|}
\hline Variables & All patients $\mathrm{N}=85$ & Survivors $\mathrm{N}=54$ & Non-survivors $\mathrm{N}=31$ & $P$ value \\
\hline Source of infection, (\%) & & & & 0.379 \\
\hline Pneumonia & $39(45.9)$ & $21(53.8)$ & $18(46.2)$ & \\
\hline Urinary tract infection & $16(18.8)$ & $10(62.5)$ & $6(37.5)$ & \\
\hline Intra- abdominal infection & $15(17.6)$ & $11(73.3)$ & $4(26.7)$ & \\
\hline Meningitis & $6(7.1)$ & $6(100)$ & - & \\
\hline Wound infection & $1(1.2)$ & $1(100)$ & - & \\
\hline Unknown infection & $6(7.1)$ & $4(66.6)$ & $2(33.4)$ & \\
\hline Others & $2(2.4)$ & $1(50)$ & $1(50)$ & \\
\hline \multicolumn{5}{|l|}{ Vital signs (mean $\pm \mathrm{SD}$ ) } \\
\hline Temperature & $99.19 \pm 2.82$ & $99.9 \pm 2.20$ & $98.3 \pm 2.3$ & 0.001 \\
\hline MAP & $59.18 \pm 19.15$ & $72.39 \pm 18.87$ & $68.31 \pm 20.76$ & 0.345 \\
\hline Heart rate & $70.32 \pm 19.74$ & $102.1 \pm 22.2$ & $107.0 \pm 20.25$ & 0.296 \\
\hline Respiratory rate & $26.75 \pm 7.11$ & $25.61 \pm 7.1$ & $28.1 \pm 7.01$ & 0.108 \\
\hline Oxygen saturation & $89.17 \pm 8.94$ & $91.61 \pm 6.1$ & $86.3 \pm 10.7$ & 0.006 \\
\hline \multicolumn{5}{|l|}{ Laboratory values (mean \pm SD) } \\
\hline WBC & $17.81 \pm 22.82$ & $14.5 \pm 8.6$ & $21.7 \pm 32.7$ & 0.149 \\
\hline Hematocrit & $32.78 \pm 8.3$ & $31.8 \pm 8.9$ & $33.9 \pm 7.3$ & 0.250 \\
\hline Lactate & $2.32 \pm 2.36$ & $1.5 \pm 1.07$ & $3.3 \pm 3.04$ & 0.000 \\
\hline Creatinine & $2.2 \pm 2.1$ & $1.8 \pm 1.5$ & $2.7 \pm 2.6$ & 0.058 \\
\hline Total bilirubin & $2.1 \pm 3.3$ & $1.3 \pm 2.2$ & $3.0 \pm 4.1$ & 0.002 \\
\hline APACHE II (mean \pm SD) & $16.011 \pm 5.62$ & $14.11 \pm 4.60$ & $19.23 \pm 5.86$ & 0.000 \\
\hline \multicolumn{5}{|l|}{ Admission } \\
\hline ICU, n (\%) & $33(38.8)$ & $18(54.5)$ & $15(45.5)$ & 0.170 \\
\hline MICU, n (\%) & $21(24.7)$ & $13(61.9)$ & $8(38.1)$ & 0.859 \\
\hline General ward, n (\%) & $31(36.5)$ & $23(74.2)$ & $8(25.8)$ & 0.165 \\
\hline LOS in ED(hours), mean \pm SD & $13.01 \pm 7.03$ & $11.67 \pm 4.84$ & $9.77 \pm 5.61$ & 0.003 \\
\hline LOS in hospital(days), mean \pm SD & $11.27 \pm 5.26$ & $11.67 \pm 4.9$ & $9.77 \pm 5.61$ & 0.106 \\
\hline
\end{tabular}




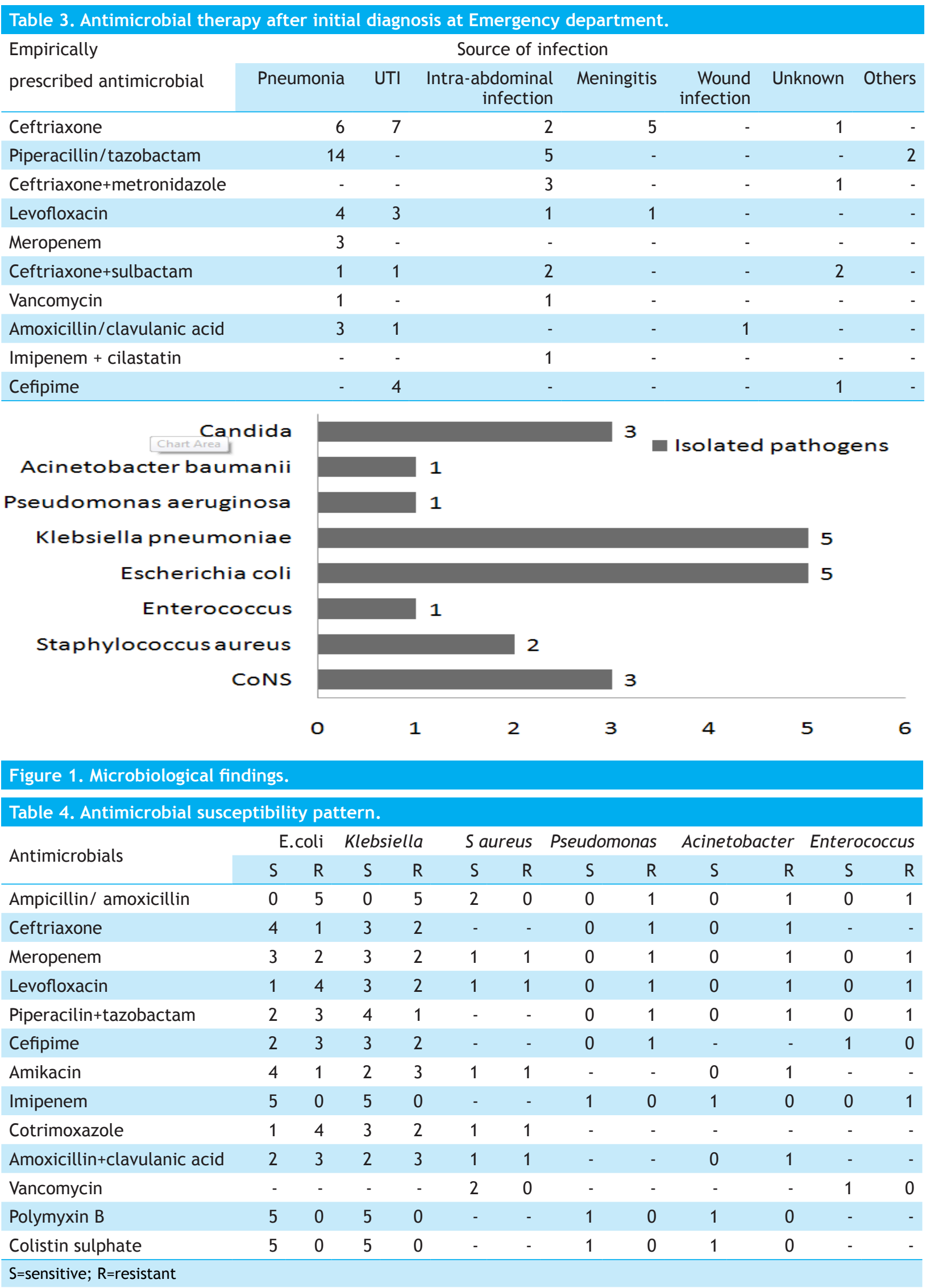


followed by ceftriaxone ( 6 patients). Similarly in case of UTI, ceftriaxone and cefepime was most commonly prescribed in 7 and 4 patients respectively. Ceftriaxone was the drug of choice for meningitis ( 5 patients) (Table 3).

All the bacterial isolates were resistant to ampicillin and amoxicillin except Staphyloccus aureus. Among 5 isolates of E.coli, the highest resistance was found with ampicillin/ amoxicillin (5) followed by levofloxacin and cotrimoxazole, 4 isolates each (Table 4).

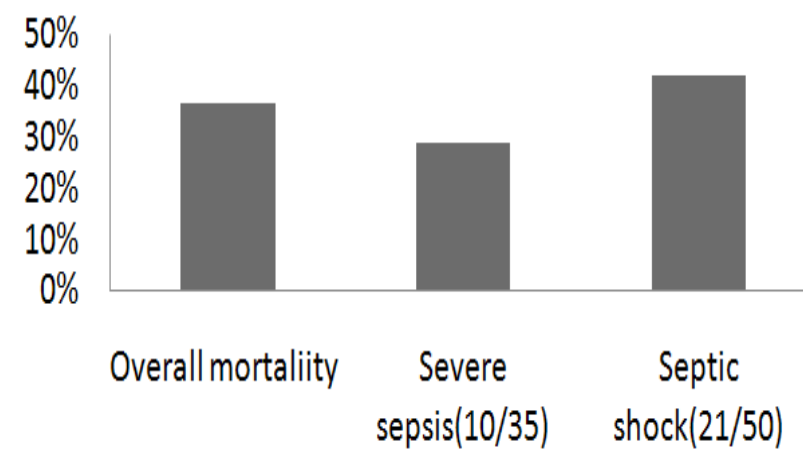

Figure 2. Mortality of patients with severe sepsis and septic shock.

The microbiological result from 21 patients with culture positive result showed that empirical antimicrobial therapy was inadequate in 4 patients. Out of 3 patients, who had Candida species isolated, 1 patient was not receiving antifungal agents as empirical therapy at ED. Acinetobactor baumanni complex was found to be multidrug resistant in a patient admitted to the ICU. Extended spectrum beta lactamase (ESBL) producing E.coli was resistant to ceftriaxone and ampicillin. Methicillin sensitive Staphylococcus aureus was isolated in 1 subject who was resistant to empirically prescribed imipenem and aminoglycoside.A greater number of patients were admitted to the ICU (38.8\%) followed by Medical Intensive Care Unit (MICU) (24.7\%) and general ward (36.5\%). The mean length of stay in ED was $13.01 \pm$ $7.03 \mathrm{~h}$, while it was $11.27 \pm 5.26$ days in hospital. (Table 2) A total of $31(36.5 \%)$ septic patients died and $63.5 \%$ were discharged from the hospital. 35 patients had severe sepsis of which 10 (28.5\%) died and out of 50 patients with septic shock 21 (42\%) died (Figure 2).

\section{DISCUSSION}

In our study, most common source of infection in septic patients was pneumonia (45.9\%), urinary tract infection (18.8\%) and acute abdominal infection (17.6\%). This is consistent with results of other studies. ${ }^{13,14}$ A study conducted at Saudi hospital reported pneumonia (36.6\%) as the most frequent source followed by urinary tract infection leading to hospitalization. ${ }^{14}$ Similarly, Aluisio et al. also reported pulmonary infection as the major medical illness among ED patients with sepsis. ${ }^{15}$ A study carried on outcome of sepsis associated acute kidney failure injury in intensive care unit recognized pneumonia the major medical illness. ${ }^{16}$

The use of vasopressor such as norepinephrine, epinephrine and dopamine were found significantly more in deceased group than in survivors. Empiric antibiotic administration is initiated in emergency department as early as possible so as to prevent further worsening of problem. ${ }^{17}$ The initiation of appropriate antimicrobial therapy at ED plays a vital role in survival of patient with sepsis and septic shock.6,7 In our study, ceftriaxone $(24.7 \%)$ and piperacillin/tazobactam $(21.7 \%)$, were the most commonly prescribed antibiotic in emergency room. Recent study on same setting also reported cephalosporin group of antibiotics as first choice for treating infections at emergency department. ${ }^{18}$ However, studies in ICU setting reported beta lactam as most frequently prescribed antibiotics. ${ }^{19,} 20$

With the fact that there are limited numbers of ICU beds available in our institution, patients remain in observation room until ICU bed is available. Thereafter patients are admitted in ICU or MICU or are referred to another hospital. Patients who improve are shifted to general ward. In this study, patients admitted to the ICU, MICU and General ward were $38.8 \%, 24.7 \%$ and $36.5 \%$ respectively. This is in accordance with a similar study carried out in Lebanon with a sample of 97 patients admitted through ED, $45.35 \%$ admitted to ICU and $54.7 \%$ were managed in general ward. ${ }^{21}$

We found that average ED and hospital length of stay were $13.01 \pm 7.03 \mathrm{~h}$ and $11.27 \pm 5.26$ days respectively. Dagher GA et al. reported average length of ED and hospital stay was $13.35 \pm 17.154 \mathrm{~h}$ and $12.04 \pm 13.951$ days respectively. ${ }^{21}$

Univariate comparisons of age, APACHE II score, vital signs, laboratory values and lactate clearance between survivors and non survivors were performed. There was a statistically significant difference between survivors and non survivors for age $(p=0.001)$, temperature $(p=0.001)$, lactate $(p=0.000)$ and APACHE II score $(p=0.000)$ similar to the findings. ${ }^{22,23}$ The predictive abilities of physiological condition of patients were scored by APACHE II ("Acute Physiology and Chronic Health Evaluation II"). In our study, the APACHE II score was $19.23 \pm 5.86$ among the non survivors, however Conde et al. reported a slight higher APACHE II score of $24 .{ }^{14}$ In our institution, 
mortality was significantly higher in patients with higher APACHE II score and preexisting co-morbid conditions.

Our inpatient mortality was $36.5 \%$ which is similar to $35.2 \%$ reported by Nguyen et. al. on patient visiting emergency department in critical condition. ${ }^{4}$ Nearly same mortality rates were reported by studies carried out by Yokota et al., (29\%) and Dagher et al., (30.9\%) on severe sepsis patients. ${ }^{17,21}$ However, a study on severe sepsis in pre- hospital emergency care reposed a lesser inpatient mortality of just $19.6 \% .^{3}$ Out of 29 patients admitted to the ICU, 16 patients passed away. Overall, patients admitted to the ICU had a greater mortality, and this can be explained by the fact that sicker patients are usually admitted to critical care units.

\section{CONCLUSIONS}

This study depicts the overall management and outcome of severe sepsis and sepsis shock patients presenting to the emergency department of a tertiary care center. Initial management of severe sepsis and septic shock with antibiotics and vasopressors are initiated in emergency department. However, increasing use of antibiotics in emergency department and ICU has led a threat to antimicrobial resistance. A higher incidence of mortality among the patients with severe sepsis and septic shock was reported in the study, suggesting that more works need to be done. The outcome could be improved if the hospital educate, aware and train its healthcare professionals on the treatment protocol.

\section{ACKNOWLEDGEMENTS}

We would like to thank all the faculty members, doctors, nurses, microbiologists and other staffs of Department of Pharmacy, Emergency Department, Anesthesiology, and Microbiology.

\section{REFERENCES}

1. Singer M, Deutschman CS, Seymour CW, Shankar-Hari M, Annane D, Bauer M, et al. The Third International Consensus Definitions for Sepsis and Septic Shock (Sepsis-3). JAMA [Internet]. 2016;315(8):801-10. [PubMed]

2. Perman SM, Goyal M, Gaieski DF. Initial Emergency Department Diagnosis and Management of Adult Patients with Severe Sepsis and Septic Shock. Scand J Trauma Resusc Emerg Med. 2012;20(1):41.[PubMed]

3. Seymour CW, Rea TD, Kahn JM, Walkey AJ, Yealy DM, Angus DC. Severe sepsis in pre-hospital emergency care: Analysis of incidence, care, and outcome. Am J Respir Crit
Care Med. 2012;186(12):1264-71.[PubMed]

4. Nguyen HB, Rivers EP, Havstad S, Knoblich B, Ressler $\mathrm{J}$ a, Muzzin a $\mathrm{M}$, et al. Critical care in the emergency department: A physiologic assessment and outcome evaluation. Acad Emerg Med. 2000;7(12):1354-61. [PubMed]

5. Lakhey S, Karki B, Shrestha B, Shakya S, Pandey SB. Sepsis: a private hospital experience in Nepal. J Inst Med 2007;28(1):12-5 [Link]

6. Garnacho-Montero J, Gutiérrez-Pizarraya A, EscorescaOrtega A, Fernández-Delgado E, López-Sánchez JM. Adequate antibiotic therapy prior to ICU admission in patients with severe sepsis and septic shock reduces hospital mortality. Crit Care [Internet]. 2015;19(1):302. [PMCID][Link]

7. Zahar J-R, Timsit J-F, Garrouste-Orgeas M, Français A, Vesim A, Descorps-Declere A, et al. Outcomes in severe sepsis and patients with septic shock: pathogen species and infection sites are not associated with mortality. Crit Care Med. 2011;39(8):1886-95.[PubMed]

8. Shaw CK, Shaw P, Thapalial a. Neonatal sepsis bacterial isolates and antibiotic susceptibility patterns at a NICU in a tertiary care hospital in western Nepal: a retrospective analysis.Kathmandu Univ Med J. 2007;5(2):153-60. [PubMed]

9. Rh C, Acharya R, Shrestha N, Br G, Bb B, Kayastha M. Bacteriological Profile of Neonatal Sepsis in Neonatal Intermediate Care Unit of Central Paediatric Referral Hospital in Nepal. J Nepal Health Res Counc. 2015;13(3):205-8. [PubMed]

10. Jain NK, Jain VM M. Clinical Profile of Neonatal Sepsis Kathmandu Univ Med J. 2003;1(2):117-20. [PubMed]

11. Dellinger RP, Levy MM, Rhodes A, Annaane D, Gerlach H, Opal SM, et. al. Surviving sepsis campaign: International guidelines for management of severe sepsis and septic shock, 2012. Intensive Care Med. 39:165-228. [DOI]

12. Knaus WA, Draper EA, Wagner DP, et al:APACHE II: A severity of disease classification system. Crit Care Med.1985; 13:818-829.[PubMed]

13. Memon JI, Rehmani RS, Alaithan AM, El Gammal A, Lone TM, Ghorab K, et al. Impact of 6-hour sepsis resuscitation bundle compliance on hospital mortality in a Saudi hospital. Crit Care Res Pract. 2012;2012.[PubMed]

14. Conde KAP, Silva E, Silva CO, Ferreira E, Freitas FGR, Castro I, et al. Differences in Sepsis Treatment and Outcomes between Public and Private Hospitals in Brazil A Multicenter Observational Study. PLoS One. 2013;8(6). [PubMed] 
15. Aluisio AR, Jain A, Baron BJ, Sarraf S, Sinert R, Legome E, et al. The prognostic role of non-critical lactate levels for in-hospital survival time among ED patients with sepsis. Am J Emerg Med. 2016;34(2):170-3. [PubMed]

16. Ghimire M, Pahari B, Sharma SK, Thapa L, Das G, Das GC. Outcome of sepsis-associated acute kidney injury in an intensive care unit: an experience from a tertiary care center of central Nepal. Saudi J Kidney Dis Transplant. 2014;25(4):912-7.[PubMed]

17. Yokota PKO, Marra AR, Martino MD V., Victor ES, Durão MS, Edmond MB, et al. Impact of Appropriate Antimicrobial Therapy for Patients with Severe Sepsis and Septic Shock - A Quality Improvement Study. PLoS One. 2014;9(11):e104475.[PubMed]

18. Joshi D, Bhandari S, Ar U, Bm R, Pn P. Empirical use of Antibiotics in Emergency Department of Tribhuvan University Teaching Hospital and Treatment Success Rate in Discharged Patients. Journal of Institute of Medicine. 2014 Dec; 36(3) :32-7.[FullText]

19. Leone M, Bourgoin A, Cambon S, Dubuc M, Albanèse J, Martin C. Empirical antimicrobial therapy of septic shock patients: adequacy and impact on the outcome. Crit Care Med. 2003;31(2):462-7.[PubMed]
20. Díaz-Martín A, Martínez-González ML, Ferrer R, OrtizLeyba C, Piacentini E, Lopez-Pueyo MJ, et al. Antibiotic prescription patterns in the empiric therapy of severe sepsis: combination of antimicrobials with different mechanisms of action reduces mortality. Crit Care. 2012;16(6):R223. [PubMed]

21. Dagher GA, Saadeldine M, Bachir R, Zebian D, Chebl RB. Descriptive analysis of sepsis in a developing country. Int J Emerg Med. 2015;8(1):19.[PubMed]

22. Nguyen HB, Rivers EP, Knoblich BP, Jacobsen G, Muzzin A, Ressler JA, et. al. Early lactate clearance is associated with improved outcome in severe sepsis and septic shock. Crit Care Med. 2004 Aug;32(8):1637-42.[DOI]

23. Ferrer R, Artigas, A., Suarez, D., Palencia, E., Levy, M. M., Arenzana, et al. Effectiveness of treatments for severe sepsis: A prospective, multicenter, observational study. Am J Respir Crit Care Med. 2009 Nov; 180(9):861-6.[DOI] 